\title{
Salvador de Mendonça: um polígrafo entre as letras nacionais e estrangeiras
}

\author{
Valéria Cristina Bezerra ${ }^{1}$
}

\begin{abstract}
Resumo: Os periódicos do século XIX conservam o nome de muitos literatos que tiveram uma relevante atuação nas letras brasileiras, mas que acabaram no esquecimento. Salvador de Mendonça (1841-1913) construiu uma trajetória semelhante às de escritores hoje canonizados, a qual the permitiu reconhecimento em seu tempo e motivou a escrita de biografias a seu respeito em meados do século XX. Nem assim obteve sua inserção nas histórias literárias brasileiras. Este artigo tem por objetivo desvelar a atuação de Salvador de Mendonça e suas posições em relação à presença da literatura estrangeira, num momento em que os literatos brasileiros estavam empenhados na consolidação da literatura brasileira. Por meio de seu exercício na imprensa, de sua colaboração com um dos mais proeminentes livreiros-editores da corte e da publicação de um romance, buscaremos verificar suas posturas e interpretar, através delas, as condições das letras no Brasil frente à coexistência da nascente literatura nacional com a intensa circulação de romances estrangeiros, atentando para as implicações desse fator na construção de uma carreira literária no Brasil no século XIX.
\end{abstract}

Palavras-chave: Salvador de Mendonça. Imprensa. Literatura brasileira. Tradução. Século XIX.

\section{Introdução}

Salvador de Mendonça foi um jornalista e homem de letras que conquistou renome em seu tempo por meio de uma produção diversa e multifacetada. Os dados de sua biografia mostram que Mendonça nasceu em Itaboraí no ano de 1841, tendo se mudado para a corte em 1853 para dar continuidade aos estudos. Em 1859, ingressou na Faculdade de Direito da província de São Paulo. No entanto, precisou abandonar o curso em 1860 devido à morte dos pais, pois a ele recaiu a responsabilidade pela manutenção da família (SÜSSEKIND DE MENDONÇA, 1960, p. 15).

O caso de Salvador de Mendonça ilustra o modo de funcionamento das letras no Brasil ao longo do século XIX: além de atender aos anseios e propósitos de elaboração da literatura brasileira, significavam uma oportunidade de remuneração para esses profissionais da pena, já que nem todos alcançavam a indicação para algum cargo público. Mendonça teve de esperar

\footnotetext{
${ }^{1}$ Pós-doutoranda do Instituto de Biociências, Letras e Ciências Exatas (IBILCE) da Universidade Estadual Paulista Júlio de Mesquita Filho (UNESP). Este trabalho foi realizado com bolsa de doutorado da Fundação de Amparo à Pesquisa do Estado de São Paulo (FAPESP). E-mail: valcrisbr@gmail.com.
} 


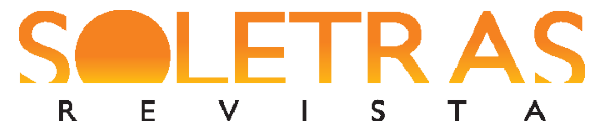

muito por uma nomeação e, enquanto isso, recorreu às letras como meio de subsistência, de construção de uma carreira e de alcance de notoriedade.

\section{As primeiras experiências na imprensa}

No começo de sua atividade, Mendonça dividia-se entre as aulas particulares e a colaboração com os periódicos da corte, como o Diário do Rio de Janeiro, o Jornal do Comércio, o Correio Mercantil, A Atualidade, através de artigos anônimos de natureza vária ou de seções de crítica musical assinadas. Por esse tempo, estreou na crítica literária. Em 1860, publicou na Revista Popular ñDuas palavras sobre um grande livroò, a respeito de Flores Silvestres, livro de poemas de Bittencourt Sampaio. Em 1863, exprimiu, por meio de um opúsculo, o seu juízo crítico sobre Calabar, de Mendes Leal. Com o subtítulo ñHistória Brasileira do século XVIIò, o romance tinha o propósito de, segundo as palavras do próprio Mendes Leal, ñcriar do Brasil e para o Brasil um gênero de literatura, para que ele parece tão afeito, e que lhe pode fazer tantos serviços reaisò (MENDES LEAL, 1863, p. 16). Contudo, no referido opúsculo, Mendonça sustentava que:

[...] o romance do Sr. Mendes Leal é um mau romance: mau porque, sem originalidade, sem coesão, enfadonho não raras vezes, peca e peca muito pelo lado literário; mau porque, desvirtuando umas melhores páginas de nossa História, levantando aleives ao passado, incutindo no ânimo nacional errada versão do que foram seus maiores, é imperdoável pelo lado histórico. ${ }^{2}$

Mendonça demonstrou na imprensa empenho na defesa de obras brasileiras e da identidade nacional, a qual Calabar não teria condições de representar. Ao lado de seu exercício nos jornais do império, Mendonça teve uma carreira diversificada. Em 1865, assumiu temporariamente o lugar de Joaquim Manuel de Macedo (1820-1888) no Imperial Colégio D. Pedro II, na disciplina de Corografia e História do Brasil. Atendendo à necessidade de concluir o bacharelado, em 1867 retomou o curso de Direito em São Paulo, onde continuou a colaborar em periódicos e a oferecer aulas particulares. Era comum os leitores dos jornais da província de São Paulo se depararem com anúncios de aulas ou cursos oferecidos por Mendonça. Esses anúncios davam conta de sua erudição:

\footnotetext{
${ }^{2} \mathrm{O}$ texto do opúsculo foi parcialmente transcrito em $A$ Regeneração. Não foi possível consultar o texto na íntegra, pois o opúsculo não foi localizado. A Regeneração, n. 34, 09 out. 1866, p. 2. Disponível em: $\langle$ http://bndigital.bn.br/acervo-digital/regeneracao/779393 $\rangle$. Acesso em: 18 ago. 2013.
} 


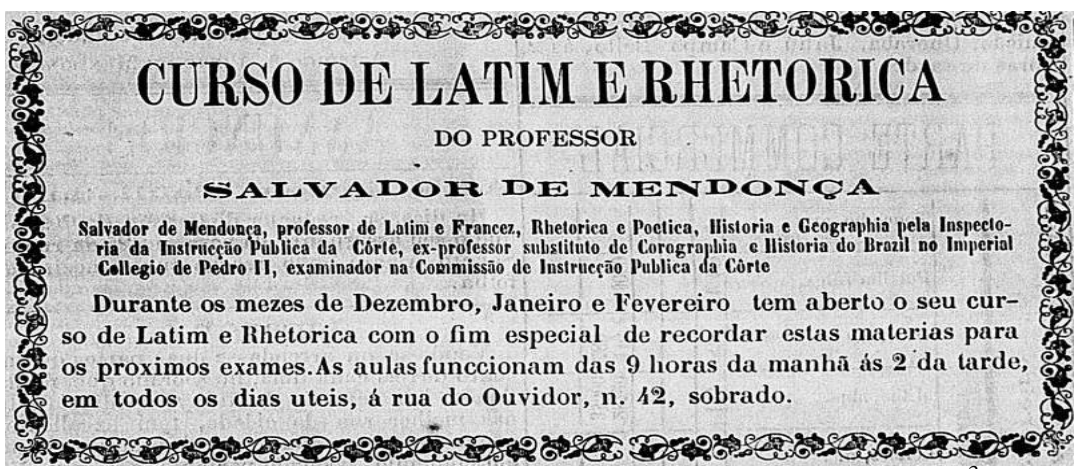

Fig. 1: anúncio de curso oferecido por Salvador de Mendonça. ${ }^{3}$

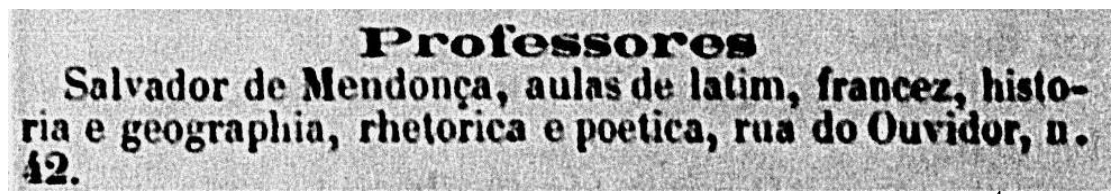

Fig. 2: anúncio de aulas oferecidas por Salvador de Mendonça.

Em fevereiro de 1868, Salvador de Mendonça passou a administrar o jornal $O$ Ypiranga, periódico de orientação liberal, com conteúdo, sobretudo, político, no qual a literatura também tinha algum espaço. O jornal contemplou a produção nacional através da publicação de poemas e de notas e artigos críticos sobre poesia e romance. Dentre esses artigos, constariam, segundo Carlos Süssekind de Mendonça, uma crítica sobre Iracema (1865), de José de Alencar (1829-1877), e outra sobre Vítimas Algozes (1869), de Joaquim Manuel de Macedo, ambas escritas por Salvador de Mendonça. ${ }^{5}$ No Ypiranga foram veiculadas ainda as cartas trocadas entre José de Alencar e Machado de Assis (1839-1908) a respeito de Castro Alves (1847-1871).

As criações estrangeiras também figuraram no espaço destinado pelo jornal à literatura. Os romances $O$ Conde de Camors (1867), de Octave Feuillet (1821-1890), e $A$ Cosaca (1866), de Paul Féval (1816-1887), foram publicados no folhetim do periódico, ambos, segundo Múcio Leão, traduzidos pelo próprio Mendonça (1952, p. 39), que se desdobrava na administração da folha, na redação dos artigos e na tradução dos romances

\footnotetext{
${ }^{3}$ O Ypiranga, n. 171, 23 fev. 1868, p. 4. Disponível em: 〈http://memoria.bn.br〉. Acesso em: 20 ago. 2013.

${ }^{4}$ O Ypiranga, n. 136, 12 jan. 1868. Disponível em: <http://memoria.bn.br >. Acesso em: 20 ago. 2013.

5 Essas críticas não foram localizadas. Os exemplares de $O$ Ypiranga conservados na Fundação Biblioteca Nacional foram mutilados com o recorte de alguns de seus textos críticos.
} 
veiculados pelo periódico. ${ }^{6}$ A presença das letras estrangeiras se deu ainda através de traduções de contos e publicações de críticas, como a de Pinheiro Chagas intitulada ño último romance de Octavio Feuilletò, sobre $O$ Conde de Camors. ${ }^{7}$ Nesse artigo, que serve de prefácio para edição em livro de sua tradução da obra, Chagas destacou as qualidades desse romance, que integrava a coleção portuguesa Jardim do Povo e ñsa[ía] a lume em Portugal quase ao mesmo tempo que o original em Françaò. ${ }^{8}$ Mesmo com o romance já disponível em língua portuguesa, aparentemente Salvador de Mendonça empreendeu nova tradução de $O$ Conde de Camors, pois o cotejo entre a versão veiculada no Ypiranga e a de Pinheiro Chagas publicada em livro em Lisboa revela que se tratam de traduções diferentes. Logo após o fim de sua veiculação em folhetins no Ypiranga, o romance foi posto à venda em volume pela casa Garraux.

A experiência de Salvador de Mendonça no Ypiranga em São Paulo sedimentou as bases de sua postura jornalística, que mais tarde foram aprimoradas na corte através de um jornalismo político ladeado pela difusão literária.

\section{Redator-chefe de $A$ República}

Com a conclusão do curso de Direito e o fim de sua atividade em $O$ Ypiranga, Salvador de Mendonça retornou à corte. Desenganado com a política liberal, participou, ao lado de outros publicistas, da fundação do Clube Republicano e da implantação de $A$ República ï propriedade do Club Republicano, periódico que difundiria os interesses do movimento, cujo primeiro número saiu a lume em 3 de dezembro de 1870. Salvador de Mendonça foi, ao início, um de seus principais redatores. Logo passou a redator-gerente e chegou a ser, em 1872, um de seus proprietários. Em setembro de 1872, acabou cedendo seus direitos de propriedade do periódico, para o qual colaborou até o final do mesmo ano (MENDONÇA, 1960).

Durante todo esse tempo, Mendonça foi voz influente ou mesmo decisiva nas escolhas de pauta do veículo. A ele, muitas vezes, dirigiam-se aqueles que buscavam publicação na folha. A República saía três vezes por semana e tinha seções fixas e estáveis, entre elas a

\footnotetext{
${ }^{6}$ Por essa época, acumulava ainda um cargo de secretário do presidente da província Saldanha Marinho, em que teve breve atuação por causa da dissolução do gabinete liberal ocorrida em julho 1868.

${ }^{7}$ A primeira parte da crítica, publicada no número 210, de 17 de abril de 1868, foi destacada do exemplar conservado na Fundação Biblioteca Nacional.

${ }^{8}$ O Ypiranga, n. 211, 18 abr. 1868, p. 3. Disponível em: 〈http://memoria.bn.br〉. Acesso em: 20 ago. 2013.
} 
seção ñFolhetimòe a coluna ñLitteraturaò. A redação da República era um espaço de encontro dos homens de letras da época, conforme relata o próprio Salvador de Mendonça em crônicas sobre suas memórias:

Em nossa sala de redação, além de políticos monárquicos que iam àquele campo neutro procurar notícias, reuniam-se artistas e literatos como Carlos Gomes, Almeida Reis, Pedro Américo, Vítor Meireles, Aurélio de Figueiredo, Eduardo de Martino, Machado de Assis, Muzzio, José de Alencar, Joaquim Serra, Luís Guimarães, e outros que, nas primeiras horas da noite, nos interrompiam todo o trabalho de redação, mas nos levavam a inspiração e o estímulo que a todos comunicam os bons e claros espíritos (MENDONÇA, 1960, p. 167).

Era natural, portanto, que temas que perpassavam o debate literário da época fizessem parte da conversação desses literatos. Disso, é possível supor que as discussões manifestadas nas páginas de A República refletiam os questionamentos e impasses que entretinham as conversas nesses serões ocorridos na redação da folha. Um desses problemas era a busca pela firmação de um espaço para a literatura brasileira frente ao gosto do público pela literatura estrangeira e sua intensa circulação pelo país. Essa dificuldade foi verificada pelo próprio Salvador de Mendonça em artigo sobre $O$ tronco do Ipê (1871), publicado na República em dezembro de 1871. Mendonça deu início à sua crítica de maneira provocativa, defendendo que ños focos de civilização são tão prolíficos para o bem como para o malò. A sentença refere-se à literatura francesa, que, no seu entender, desempenhava uma ñinfluência benéfica [...] na literatura das demais nações latinasò, assim como provocava ñum influxo pernicioso nos escritores de Portugal e Brasilò. A causa do efeito danoso da literatura francesa estaria na difusão dos romances de escritores populares franceses entre o público brasileiro e português. Como consequência, os escritores desses dois países, atendendo à demanda dos editores e do público, buscariam compor as suas obras coadunadas com os aspectos responsáveis pelo sucesso dos escritos de Xavier de Montépin, Paul Féval, Ponson du Terrail. Como solução para o prejuízo dessa interferência, Mendonça propôs:

Dentre os paliativos só há recomendar aos romancistas que se esqueçam de Ponson e dos editores, e estudem, senão nos grandes modelos da antiguidade em que as letras já foram um sacerdócio, ao menos no amplo livro da natureza que aqui mais do que em parte alguma se nos abre cheio de 
formosura e brilhantismo, capaz de inspirar as mais imorredouras criações da arte. $^{9}$

A orientação não representava nenhuma novidade para as letras brasileiras: a cor local, segundo Mendonça, seria uma forma de fugir ao estigma da imitação e de conceber uma literatura nacional original. José de Alencar seria um exemplo de eficiência na aplicação dessa fórmula, destacando-se como ñ poeta que com maior brilho há até hoje inscrito o nome em nossos anais literáriosò ${ }^{10}$. Mas a inscrição do nome de Alencar nos anais literários brasileiros, para usar as palavras de Mendonça, não se deu de maneira isenta das questões impostas pela produção estrangeira, sobretudo pela intensa presença dos romances dos escritores populares franceses na corte. Menos isento ainda foi o papel de Mendonça no âmbito das letras brasileiras, pois, como se viu, enquanto editor de $O$ Ypiranga e de $A$ República, deu espaço às produções nacionais e estrangeiras, assim como deu voz a críticos brasileiros e estrangeiros que traduziram o teor dessas disputas em seus artigos. Mendonça foi um incentivador da literatura nacional, postura verificável nesse texto sobre $O$ Tronco do Ipê e também nas próprias palavras de Alencar, que no prefácio ñßenção Paternaò reconheceu o empenho do crítico, juntamente com outros colegas: ñAos amigos, como Joaquim Serra, Salvador de Mendonça, Luiz Guimarães, e outros benévolos camaradas; tu lhes dirás, livrinho, que te poupem a qualquer elogioò (ALENCAR, 1872, p. VIII). Contudo, com a diminuição de sua participação nas atividades de A República, seguida de sua saída da folha, Mendonça precisou buscar meios para a continuidade de sua atividade nas letras, e não foi a literatura brasileira que lhe proporcionou as chances de exercício profissional.

\section{As traduções para a casa de B.-L. Garnier}

Após a saída de Mendonça da República, o escritor encontrou uma remuneração atuando como tradutor junto a Baptiste-Louis Garnier. Na década de 1870, Garnier desenvolveu um empreendimento editorial voltado para a tradução de romances populares, principalmente franceses. O editor inseriu no mercado de livros no Brasil, durante esse decênio, em torno de 80 romances, vertidos por 17 tradutores, dentre os quais figurava Salvador de Mendonça, a quem recaiu a tradução de 20 títulos. Dentre as obras solicitadas,

\footnotetext{
9 A República, n. 224, 31 dez. 1871, p. 1. Disponível em: <http://bndigital.bn.br/acervodigital/republica/138916>. Acesso em: 21 ago. 2013.

${ }^{10}$ A República, n. 224, 31 de dezembro de 1871.
} 
consta, por exemplo, o prestigiado Noventa e três (1874), de Victor Hugo, assim como $O$ Sobrevivente (1873), de Paul Féval, escritor cuja acolhida pelos leitores e editores no Brasil, como vimos, havia sido anteriormente censurada por Mendonça, que considerava suas obras nocivas para o gosto do público e para o florescimento da literatura nacional. A razão para tal mudança de pensamento talvez se explique por sua situação financeira, como sugere uma correspondência que enviou a seu amigo Francisco Ramos da Paz: ñHoje preciso que me arranje quarenta mil réis; manda-môs pelo portador, pois preciso pagar à venda o mês passado. Dentro em 3 ou 4 dias destinados ao serviço da grosa e da lima [de um romance], conto meter-me nos cobres do Garnier, e a coisa seguirá em novidadeò. A carta, datada de novembro de 1872, antecede de alguns meses a publicação da primeira tradução feita por Mendonça. Não sabemos identificar se o romance mencionado na carta trata-se de uma obra original ou de tradução. O que os dados mostram é que Mendonça passou a receber os cobres de Garnier por sua atividade enquanto tradutor.

O nome de Mendonça aparecia com bastante destaque nos anúncios, nas resenhas e nas edições em livro dessas traduções, o que pode ser percebido como uma estratégia para chamar a atenção do público para as obras, através do reconhecimento que Mendonça detinha em meio aos leitores. Numa das resenhas, lê-se: ñDe todos quantos livros traduzidos tem sido editor o Sr. Garnier, ainda nenhum foi com tanto gosto e escrupulosa exatidão vertido como João de Thommeray. Isto que parece extraordinário, não causará surpresa, quando se souber que o tradutor é Salvador de Mendonçaò. ${ }^{11}$ Em nota sobre O Mateiro ou os Bandeirantes, tradução de Les coureurs des bois (1850), de Gabriel Ferry, informa-se que a versão é ñdevida à pena de um dos nossos mais distintos literatos, o Sr. Dr. Salvador de Mendonçaò. ${ }^{12}$ Na edição de Avatar, de Théophile Gautier (1811-1872), o nome de Mendonça foi impresso com maior realce que o do próprio autor, que já detinha em seu tempo grande prestígio:

\footnotetext{
${ }^{11}$ A Reforma, n. 153, 08 jul. 1873, p 2. Disponível em: 〈http://bndigital.bn.br/acervo-digital/reforma/226440 $>$. Acesso em: 25 ago. 2013.

${ }^{12}$ A Reforma, n. 120, 29 maio 1874, p. 3. Disponível em: 〈http://bndigital.bn.br/acervo-digital/reforma/226440>. Acesso em: 25 ago. 2013.
} 


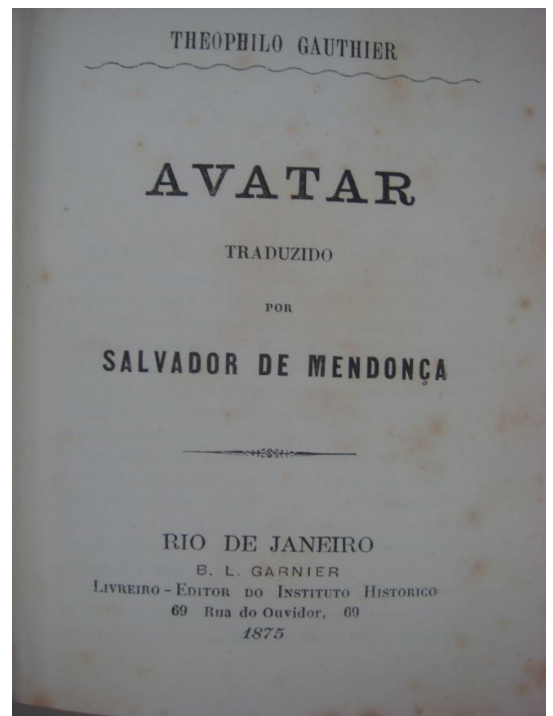

Fig. 3: Folha de rosto da tradução de Avatar. ${ }^{13}$

A atuação de Mendonça enquanto tradutor não desmerecia seu papel nas letras brasileiras, pois, ao contrário do que apregoou em sua crítica sobre as traduções de romances populares, muitas dessas obras acabaram sendo bem acolhidas pelos literatos, que as consideravam um contributo para a consolidação das literatura no país: ñcongratulamo-nos ainda uma vez com a sociedade brasileira, que mal desperta aos esplendores dôrte, pelo desenvolvimento que as letras pátrias vão realizando, já pelos esforços reais do editor [B.-L. Garnier], já pela escolha acertada de seus tradutoresò. ${ }^{14} \mathrm{O}$ trabalho de tradução, assim como o de criação original, parecia concorrer para o estabelecimento da literatura nacional, na qual Salvador de Mendonça esteve empenhado, por meio da escrita de críticas, da criação de obras próprias e, ao ver dos críticos e jornalista, de seu exercício de tradução. Dentre as obras vertidas por Mendonça, constam aquelas de autores que entraram para o cânone, como Théophile Gautier, Alfred de Musset (1810-1857), Jules Sandeau (1811-1883), Jules Verne (1828-1905) e Victor Hugo, assim como de autores populares em seu tempo que acabaram caindo no esquecimento. O gráfico abaixo apresenta o número de obras traduzidas por Mendonça de acordo com seus autores:

${ }^{13}$ GAUTIER, Théophile. Avatar. Tradução de Salvador de Mendonça. Rio de Janeiro: B.-L. Garnier, 1875. Exemplar disponível na Coleção Oficina do Livro ñRubens Borba de Moraesò, da Biblioteca Central Cesar Lattes, da UNICAMP.

${ }^{14}$ O Cearense, 19 nov. 1874, n. 95, p. 2. Disponível em: 〈http://bndigital.bn.br/acervo-digital/cearense/709506>. Acesso em: 29 ago. 2013. 


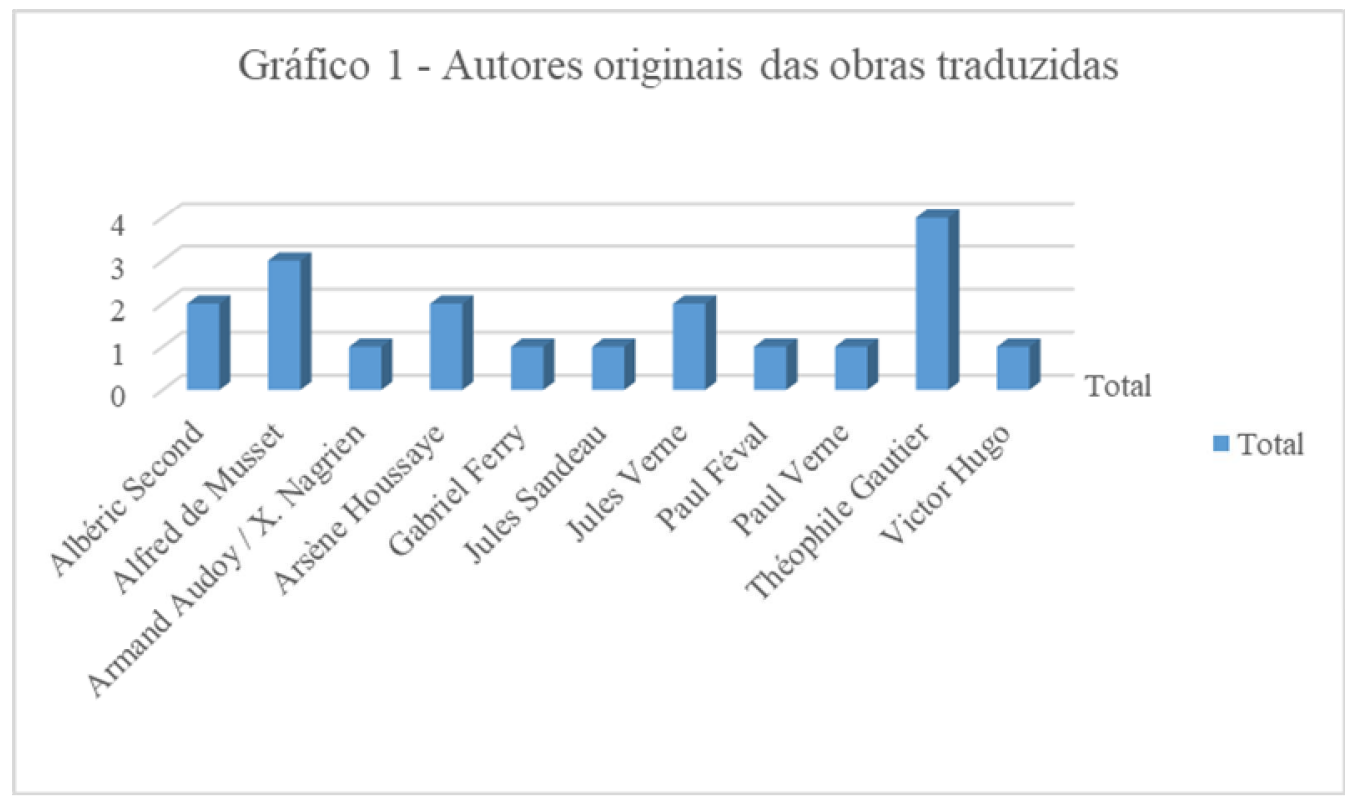

Gráfico 1: Autores originais das obras traduzidas por Salvador de Mendonça entre 1872 e 1876.

O biógrafo de Mendonça, Carlos Süssekind de Mendonça, afirma que a escolha dos títulos era feita pelo editor, que lhe encomendava as traduções (1960, p. 86). Um trabalho de cotejo entre as versões originais e vertidas ainda resta a ser feito, a fim de revelar o caráter de suas traduções, já que não dispunha de muito tempo para a realização da tarefa, dada a velocidade que a circulação de impressos ia adquirindo nessas últimas décadas do Oitocentos, quando o público ansiava pela venda no Brasil dos mais recentes romances saídos na França. A edição de Noventa e três, longamente esperada por leitores em todo o mundo, foi anunciada pela casa Garnier em versão em língua portuguesa apenas três meses após seu lançamento em Paris pela Michel Lévy. O prestígio conquistado por Mendonça até então, que lhe permitiu assinar seu nome ao lado de autores famosos, sobretudo do expoente Victor Hugo, não parece ter sido suficiente para os seus interesses. Mais uma vez, Mendonça buscou diversificar sua atuação nas letras do país.

\section{O romance Marabá}

Salvador de Mendonça angariou maior reconhecimento em 1875, com a publicação de Marabá, pela Tipografia do Globo. Antes o romance fora publicado em folhetins no jornal $O$ Globo, entre 21 de dezembro de 1874 e 9 de fevereiro de 1875, e em $O$ Mercantil, de Petrópolis, de $1^{\circ}$ de maio de 1875 a 21 de julho do mesmo ano. O romance conta a história de Lúcia e Agenor, amigos de infância afastados durante dez anos devido à partida de Agenor 
para os Estados Unidos, após a morte de sua mãe. De volta, reencontrou sua ama Marabá, personagem mestiça que dá título ao romance, e Lúcia, por quem sentiu reacender o seu amor de infância. A jovem, depois de passar dois anos internada em um convento, havia retornado para a casa dos pais. Rejeitava então todos os pretendentes, só não conseguia rejeitar Agenor, por quem se sentia apaixonada. A velha Marabá, espécie de feiticeira, agourou o casamento e tentou dissuadir Agenor da união, pondo em questão a virtude de Lúcia. A dúvida sobre sua fidelidade perpassa o romance, mas, com o repertório de leituras da época, era bem fácil para os leitores anteverem o desenlace:

ï [...] O senhor já leu um opúsculo de um escritor francês que aí há, filho de Alexandre Dumas, no qual se arrazoa [...] acerca da conveniência de matar ou perdoar à mulher que se torna infiel ao marido?

ï Ainda não li, Sr. desembargador. E qual é a opinião de Dumas Filho?

ï A minha! Acudiu o desembargador: que se deve matar!

[...]

ï Pois eu penso de modo inteiramente diverso, Sr. desembargador. O autor da Dama das Camélias poderá ter hoje boa razão para modificar as opiniões que o levaram a iniciar a propaganda da reabilitação da mulher; mas a não ser em épocas obscurantistas e em costumes bárbaros e anacrônicos não sei onde terá ido buscar fundamento para a sua nova doutrina. ${ }^{15}$

O discurso progressista de Agenor não serviu para si próprio, uma vez que estrangulou Lúcia na noite de núpcias ao ouvir-lhe a confissão de que se entregara a outro homem. $\mathrm{O}$ romance dialoga com temas recorrentes na literatura estrangeira e guarda elementos que eram empregados na caracterização da nacionalidade, como a cor local, a miscigenação, a convivência de raças, o retrato dos costumes. Devido à atuação política e partidária de Salvador de Mendonça a favor da República, esse romance apresenta também caráter panfletário contra o regime monárquico e contra a política dos conservadores e liberais, posicionando-se a favor do modelo político dos Estados Unidos, cuja defesa era feita através da voz de Agenor. A edição em livro do romance contou com um texto de apresentação de autoria do próprio Mendonça, no qual expressou o seu desejo de contribuir com o romance para a firmação da nacionalidade da literatura brasileira:

Natural é, porém, que concorram todos, na proporção de suas forças, para o desenvolvimento da literatura nacional, e é muito provável que, no meio da geral indiferença por tais cometimentos, o presente romance nunca viesse a lume, se tivesse de esperar mão mais detida, e não nascesse da própria

$15 O$ Mercantil, $\quad$ n. 48, 26 jun. 1875, p. 2. Disponível em: <http://bndigital.bn.br/acervodigital/mercantil/376493 >. Acesso em: 05 set. 2013. 
necessidade de expansão que é dote do espírito humano (MENDONÇA, 1875 , p. VI).

O romance foi antecedido ainda de uma apreciação de José de Alencar, feita originalmente em carta pessoal destinada a Mendonça, que a transcreveu no início do volume. $\mathrm{Na}$ carta, Alencar fez elogios e reparos ao romancista:

Felicito-o por seu romance, que li com extremo prazer. Escrita no meio de graves preocupações que lhe repartiam o espírito; e sob a desagradável influência da frieza de que a indiferença pública entre nós cerca aos que trabalham; a Marabá não mostra todo o quilate de sua inspiração, nem dá a medida de seu talento, conhecido e provado em outras províncias literárias (ALENCAR, in MENDONÇA, 1875, p. VII).

A carta desempenhou um papel relevante na recepção que a obra teve na imprensa. $\mathrm{O}$ próprio jornal $O$ Globo fez menção à missiva para promover o romance, publicado em suas páginas e em volume pela sua própria tipografia: ñSalvador de Mendonça acaba de ser sagrado talento superior por José de Alencar ï o mestre desta geraçãoò. ${ }^{16}$ Em A Reforma, uma crítica assinada por Dr. Malignus destacou que Mendonça ñacaba de revelar-se o romancista de primeira ordem, na sua Marabáò e reconheceu a contribuição da obra para o enriquecimento da literatura nacional: ñFinalmente, meu amigo, a literatura pátria vai se avolumando aos poucos, um lugar de honra merece sem dúvida a Marabá. Deem-lho os críticosò. $^{17}$

O romance rendeu ainda uma polêmica: um crítico anônimo escreveu para o jornal $O$ Globo uma longa resposta a uma crítica negativa publicada num folheto satírico intitulado $O s$ Ferrões. No artigo, o colaborador de $O$ Globo rebateu de forma pontual algumas das alegações que pautaram o opúsculo. Uma de suas respostas centrou-se na censura feita à linguagem da personagem Marabá: ñApólogos pedantescos chamam os críticos dos Ferrões à linguagem figurada e pitoresca da mestiça, e que é a linguagem dos de sua raça. Marabá é pedante como Peri, como Iracema, como Ubirajara, como todos os seusò. Depois de boa parte da obra de Alencar realizada e de seu destaque no meio literário, o escritor tornava-se parâmetro para a avaliação da produção nacional. Já quando o crítico pretendeu contrapor o romance de Mendonça com obras que ofereceriam problemas, foi ao romance estrangeiro que ele recorreu: ñIncoerente assim, e pela mesma razão, é o caráter do conde de Camors, e ainda

\footnotetext{
${ }^{16}$ O Globo, n. 47, 17 fev. 1875. Disponível em: 〈http://memoria.bn.br〉. Acesso em: 10 set. 2013.

${ }^{17}$ A Reforma, n. 50, 07 mar. 1875, p. 3. Disponível em: 〈http://bndigital.bn.br/acervo-digital/reforma/226440〉. Acesso em: 12 set. 2013.
} 
ninguém lembrou-se de apontar como defeito no romance de Feuillet ó desarmônico colorido dos caracteres $\hat{\omega} .{ }^{18}$

Nesse mesmo ano de 1875, Mendonça interrompeu sua atividade literária no Brasil para atuar no consulado de Nova York. Em carta a Machado de Assis em 7 de março de 1876, Mendonça informou a respeito de um segundo romance que estaria em conclusão, mas não se tem notícia de sua publicação (2009, p. 112). Marabá acabou sendo seu único romance. Contudo sua atividade em prol da literatura nacional foi bastante variada, pois, além dos inúmeros artigos de teor político e cultural que escreveu para a imprensa e do romance Marabá, produziu ainda poemas, peças de teatro, estudos históricos e biográficos e vários ensaios sobre o Brasil durante seu exercício de diplomata. Todos esses textos contribuíam para a conformação da imagem de nação, uma vez que defendiam a arte nacional e discutiam a política e história no país.

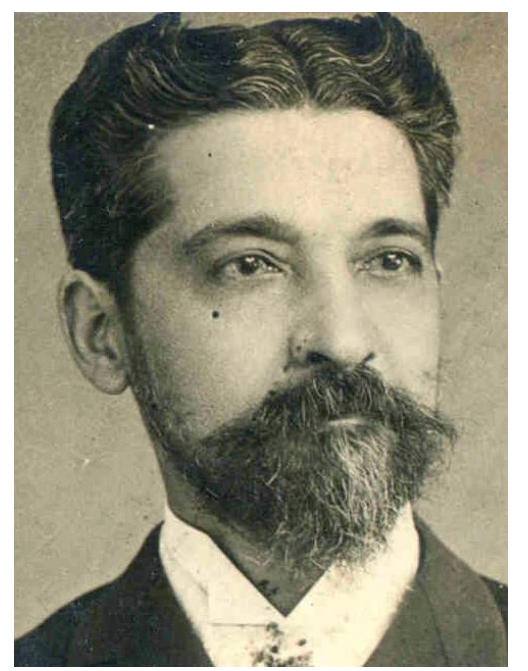

Fig. 4: Salvador de Mendonça em 1890, por Mathew Brady, Portraits of Delegates to the International American Conference, Washington, D.C., 1889-1890. ${ }^{19}$

\section{Conclusão}

Apesar da trajetória de destaque e reconhecimento em seu tempo, Salvador de Mendonça tornou-se em nossos dias um escritor desconhecido. Houve esforços na recuperação de seu nome por meio da publicação de biografias e de suas memórias já no

\footnotetext{
${ }^{18}$ O Globo, n. 340, 13 dez. 1875. Disponível em: 〈http://memoria.bn.br〉. Acesso em: 10 set. 2013.

${ }^{19} \mathrm{https} / /$ pt.wikipedia.org/wiki/Salvador_de_Mendon\%C3\%A7a. Acesso em: 30 ago. 2017.
} 
século XX, mas não foram suficientes para permitir o seu ingresso na história literária tradicional. O caso de Salvador de Mendonça ilustra o modo de funcionamento do ambiente das letras no Brasil e revela a implicação da presença e circulação da produção estrangeira em seu exercício como jornalista, como tradutor e como autor de obras originais, atividades que dialogavam com esse ambiente diverso proporcionado pela convivência entre as obras nacionais e estrangeiras. Os escritos de Mendonça revelam os impasses enfrentados em busca da consolidação da literatura nacional e o papel da literatura estrangeira no processo de elaboração de uma imagem literária própria.

Salvador de Mendonça atuou num dos períodos mais acesos do debate literário no Brasil, e o estudo de sua trajetória lança luz sobre muitos dos aspectos que permearam a construção da carreira nas letras naquele momento. O jornal significava, muitas vezes, o primeiro passo para esse ingresso. Nesse espaço, Mendonça, a exemplo de seus pares, estabeleceu contatos, criou círculos de amizade e, com isso, obteve sua nomeação para postos de chefia nas redações. Pôde, então, dar visibilidade para outros escritores e para si próprio, propiciando sua notoriedade. A partir daí, despertou a atenção de um editor, que publicou, não obras de sua autoria, mas traduções, que lhe asseguraram uma atuação profissional e uma renda. Tal função lhe proporcionou maior reconhecimento, o que lhe favoreceu a publicação de uma obra de sua autoria em folhetim e em livro por uma renomada folha da corte. Com uma carreira feita, respeitado nos mais prestigiados círculos da corte, alcançou enfim um relevante posto público, ao qual aspiravam tantos outros que buscavam construir uma reputação através da pena. Recrutados por uma imprensa em desenvolvimento, assim como Salvador de Mendonça, muitos conseguiram sair do anonimato, mas, assim como ele, acabaram sendo lançados ao esquecimento pela história literária.

\section{Referências}

ALENCAR, José de. Benção Paterna. In: . Sonhos dôOuro. Rio de Janeiro: B.-L. Garnier, 1872.

Carta de 12 de fevereiro de 1875 a Salvador de Mendonça. In MENDONÇA, Salvador de. Marabá: romance brasileiro. Rio de Janeiro: Tipografia do Globo, 1875.

CORRESPONDÊNCIA de Machado de Assis. Tomo II, 1870-1889. Coordenação e orientação de Sérgio Paulo Rouanet. Rio de Janeiro: ABL, 2009.

DUMAS FILS, Alexandre. Lôhomme-femme: réponse à M. Henri dđ̂deville. Paris : Michel Lévy Frères éditeurs, 1872. 
LEÃO, Múcio. Salvador de Mendonça: ensaio biobibliográfico. Rio de Janeiro: Publicações da Academia Brasileira, 1952.

MENDES LEAL JUNIOR, José da Silva. Calabar: História Brasileira do século XVII. Rio de Janeiro: Tipografia do Correio Mercantil, 1863.

MENDONÇA, Carlos Süssekind de. Salvador de Mendonça: democrata do Império e da República. Rio de Janeiro: Instituto Nacional do Livro, 1960.

MENDONÇA, Salvador de. ñCousas do meu tempoò. In Revista do Livro, n. 20. Rio de Janeiro: Ministério da Educação e Cultura, dezembro de 1960. Marabá: romance brasileiro. Rio de Janeiro: Tipografia do Globo, 1875.

\title{
Periódicos consultados
}
A Reforma
A Regeneração
A República
O Cearense
O Globo
O Mercantil
O Ypiranga

\section{Salvador de Mendonça: a polygraph between Brazilian and foreign letters}

\begin{abstract}
The periodicals of the nineteenth century preserve the names of many literary figures of note in Brazilian literature, yet the memory of whom has faded. Salvador de Mendonça took a path that, like those of writers of today's canon, granted him recognition in his time and led to the writing of biographies about him in the mid-twentieth century. Nevertheless, his name did not make it into Brazilian literary histories. The objective of this article is to reveal Salvador de Mendonçaôs presence and his views on foreign literature in Brazil at a moment when the literati of the country were engaged in establishing Brazilian literature. By means of his activity in the press, his collaboration with one of the foremost bookseller-publishers of the court and the publication of a novel, we will aim at verifying his attitudes and through them interpret the conditions for literature in Brazil given the emerging national literature with the intense circulation of foreign novels and attempt to understand the implications of this factor in the forging of a literary career in nineteenth-century Brazil.
\end{abstract}

Keywords: Salvador de Mendonça. Press. Brazilian literature. Translation. Nineteenth century.

Recebido em: 29 de agosto de 2017.

Aprovado em: 07 de outubro de 2017. 